ARTICLE

\title{
Juvenile idiopathic arthritis - an update on its diagnosis and management
}

\author{
C Scott, MB ChB, FCPaed (SA), Grad Cert Paed Rheum (UWA); N Brice, MB ChB, Dip HIV Man (SA), FCPaed (SA) \\ Paediatric Rheumatology, Institute of Child Health, Red Cross War Memorial Children's Hospital and University of Cape Town, South Africa
}

Corresponding author: C Scott (chris.scott@uct.ac.za)

Juvenile idiopathic arthritis (JIA) is the most common form of chronic arthritis in children and the most common cause of musculoskeletal disability in children. Early diagnosis may be challenging, but it is essential to ensure good outcomes. This review proposes an approach to the investigation and diagnosis of JIA. It also gives a summary of the latest available evidence-based treatment for this disease.

S Afr Med J 2015;105(12):1077. DOI:10.7196/SAMJ.2015.v105i12.10223

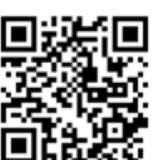

Musculoskeletal (MSK) complaints are very common in children, who present to general practitioners, paediatricians and orthopaedic surgeons. Studies have reported that they may occur in $4-30 \%$ of the community. A Scottish study showed that 1 in every 58 children presenting to a paediatric accident and emergency unit had limping as their primary complaint, and a survey of adolescents in British Columbia revealed that MSK complaints were viewed as the most common health concern after acne. ${ }^{[1-4]}$ The differential diagnosis for a child presenting with MSK pain ranges from dreadful to completely benign (Table 1 ).

An accurate diagnosis of juvenile idiopathic arthritis (JIA) depends on a good clinical approach, clues derived from the history and examination, and pattern recognition, which will assist the clinician in making the diagnosis. A thorough history and examination are the most important tools to make the diagnosis of JIA, where early diagnosis and treatment have been shown to directly improve outcomes. ${ }^{[5]}$ Children are constantly growing and developing, and changing milestones, anatomy and physiology increase the difficulty of making the diagnosis of JIA.

\section{Methods}

This brief review summarises the available and relevant evidence on the diagnosis and management of JIA in the South African (SA) context and is intended to assist the non-specialist in the identification,

\section{Table 1. Common causes of joint pain}

- Reactive arthritis

- Juvenile idiopathic arthritis

- Septic arthritis/osteomyelitis

- Haemarthrosis (e.g. haemophilia)

- Infections (e.g. tuberculosis)

- Malignancy (e.g. acute lymphoblastic leukaemia)

- Rheumatic fever

- Benign nocturnal MSK pains of childhood (growing pains)

- Benign hypermobility syndrome

- Mechanical, e.g. Osgood-Schlatter disease, slipped upper-femoral epiphysis

- Avascular necrosis (e.g. Perthes disease)

- Trauma management and referral of these patients. Sources of relevance were drawn from published medical literature (searched via Medline), authoritative texts and online resources on paediatric rheumatology.

\section{Table 2. Juvenile idiopathic arthritis subtypes}

\begin{tabular}{ll}
\hline JIA subtype & Characteristics \\
\hline Oligoarticular & Younger child \\
& More common in females than in males \\
& $1-4$ affected joints in first 6 months \\
& ANA positive in up to $70 \%$ \\
& Uveitis - common \\
Extended oligoarticular & $>4$ joints after first 6 months \\
Polyarticular RF & $\geq 5$ affected joints in first 6 months \\
negative & RF negative \\
& Younger child \\
& More common in females than in males \\
& ANA positive in $~ 40 \%$ \\
Polyarticular RF & $\geq 5$ joints in first 6 months \\
positive & RF positive $\times 2$ (3 months apart) \\
& More common in females than in males \\
Enthesitis-related & Adolescents \\
arthritis & HLA B27 positive \\
& Sacroiliitis \\
& Inflammatory backache \\
& Family history of HLA B27-related disease \\
& Usually older boys ( $>7$ years) \\
HLA = human leukocyte antigen; & ANA = antinuclear antibody; RF = rheumatoid factor. \\
Psoriatic arthritis & Psoriasis \\
& Dactylitis \\
& Psoriasis in 1st-degree relative \\
& Nail pitting \\
& Fever - daily \\
& Rash \\
& Hepatosplenomegaly \\
& Serositis \\
& Raised ferritin \\
& Complicated by macrophage activation \\
& syndrome \\
&
\end{tabular}




\section{Epidemiology}

JIA is the most common chronic MSK condition in children and the most common cause of MSK disability. Although it is perceived as a rare disease it is no less common than many other childhood diseases such as epilepsy and diabetes, and community-based studies indicate that a prevalence of between 1 and 4 per 1000 children is affected. ${ }^{[6]}$ The wide variation in prevalence rates between studies could in part be accounted for by differences in study design and lack of standardised definitions of JIA in earlier studies. Underdiagnosis and delays in presentation are thought to account for the low prevalence in hospital- and clinic-based studies.

\section{Terminology and classification}

JIA is the World Health Organization (WHO)'s accepted terminology for children $<16$ years of age who have chronic arthritis (lasting $>6$ weeks) and in whom no other specific cause of arthritis can be identified. ${ }^{[7]}$ The terms juvenile chronic arthritis and juvenile rheumatoid arthritis are outdated and no longer preferred. Studies from developing countries such as SA and India appear to suggest that polyarticular JIA is more prevalent in these populations than oligoarticular JIA, which predominates in populations in Europe and the USA. ${ }^{[8]}$
For the purpose of classification, JIA is divided into 7 heterogeneous subtypes with specific clinical and pathophysiological characteristics (Table 2). Knowledge of patterns of JIA is useful in making an accurate diagnosis. A swollen knee and uveitis in a young girl, for instance, is typical of oligoarticular JIA. An older boy with Achilles insertion pain or arthritis of the first metatarsophalangeal joint is typical of juvenile enthesitis-related arthrtitis (ERA). Dactylitis and asymmetrical largeand small-joint arthritis are seen in patients with psoriatic arthritis, whereas symmetrical small-joint involvement in an older girl is typical of rheumatoid factor (RF)-positive polyarticular JIA.

\section{Pathophysiology}

The cause of JIA is not known, although it is accepted that some type of interplay between environmental factors (e.g. infections or the gut microbiome) and complex genetic factors leads to a disturbance in the balance between immune tolerance and inflammation. Certain human leukocyte antigen (HLA) (class I and II) and non-HLA genes have been associated with different types of JIA..$^{[9]}$ Some subtypes of JIA appear to be more autoimmune in their pathophysiology than others, with adaptive and humoral immunity playing a major part. RF-positive polyarticular JIA, for instance, is strongly associated with the presence of antibodies against RF and cyclic-citrullinated peptide

Table 3. Taking a history in suspected juvenile idiopathic arthritis

Onset of pain

Timing of pain

Intensity of pain

Disability

Response to medication

Other systemic features

Family history

Social history and exposure to infectious diseases
Pain with sudden onset suggests acute conditions such as an injury or septic arthritis. JIA often has a very indolent onset and it is sometimes difficult for the child or parent to remember when the pain started. It is very important to note that the absence of reported pain does not exclude arthritis.

Early-morning stiffness and so-called 'gelling' suggest inflammatory pain. The child only limps first thing in the morning and recovers for the rest of the day.

Pain that improves with rest and worsens with activity is usually mechanical.

Nocturnal pain, commonly in the lower limbs, which disappears by morning, never occurs during the day and is not associated with any other symptom, is typical of benign nocturnal limb pains of childhood, also known as growing pains.

Nocturnal bone pain associated with fever, malaise, pallor and petechiae would obviously suggest haematological malignancy. These patients have persistent constitutional or MSK complaints during the day.

Patients with benign hypermobility suffer from pain in the evening after an active day, while their symptoms may improve with rest.

The pain caused by JIA is not frequently reported as severe. Entheseal inflammation or tenosynovitis, however, can be acutely painful despite a relative absence of clinical signs of swelling or joint limitation.

The pain in amplified pain syndromes or complex regional pain syndromes can be extremely intense and persist throughout the day, causing major disability.

Septic arthritis is also acutely painful, frequently resulting in a frozen joint, where the child expresses anxiety at the prospect of motion of the joint.

Children with early JIA frequently find ways to continue their activities of daily living, and function relatively well.

Children with amplified pain syndromes may have severe functional impairment, despite minor clinical findings.

Children with JIA or osteoid osteomas frequently respond well to non-steroidal anti-inflammatory drugs. This is not the case with conditions such as amplified pain or bone pain caused by malignancy.

Raynaud's phenomenon, which is common in children with scleroderma and SLE, is frequently not reported until direct enquiry. The presence of psoriasis, gastrointestinal symptoms, fever, rash or a bleeding tendency can all point in the direction of an underlying cause for arthritis.

A family history of psoriasis is essential. Similarly, a family history of ankylosing spondylitis, inflammatory bowel disease and SLE may increase the risk of these conditions.

A family history of sickle cell disease is important, especially in a child presenting with dactylitis, septic arthritis or avascular necrosis.

A social history of infections such as HIV or TB is an essential component. A preceding history of infection, especially viral or dysenteric, is crucial. 
(CCP), and $\mathrm{CD} 4 \mathrm{~T}$-cells play a role in propagating the inflammatory response. Systemic JIA, however, is an autoinflammatory disease driven by abnormalities of the innate immune system, with neutrophils and macrophages playing the major pathogenic roles.

\section{Approach to diagnosis \\ Taking a history in a child with suspected JIA}

A good history with appropriate focus on the relevant symptoms and signs of JIA and other conditions in the differential diagnosis is very important in diagnosing JIA. Table 3 summarises the relevant aspects of history-taking in a patient with suspected JIA.

\section{Examination}

A child presenting with joint pain or MSK symptoms should have a full examination of all systems and not just of the MSK system. A basic paediatric examination, including anthropometry and vital signs (as well as blood pressure), is crucial. This not only helps to diagnose or exclude non-rheumatic illnesses that may present with MSK pain, but also to find signs associated with many of the rheumatic diseases. Red flag signs for malignancy include the following: fever, malaise, weight loss, pallor, petechiae, nocturnal bone pain, constant symptoms, unexplained bruising and lymphadenopathy.

It is important to note that children with JIA (or their parents) do not always report pain or limitation in their joints, especially the younger age groups. It is crucial that a thorough examination is undertaken to identify all active joints.

\section{Table 4. Paediatric gait, arms, legs, spine screening} examination

Screening Do you (or does your child) have any pain or stiffness questions in the joints, muscles or back?

Do you (or does your child) have any difficulty getting dressed without any help?

Gait Do you (or does your child) have any difficulty going up and down stairs?

Observe the child walking and turning.

'Walk on your tip-toes/walk on your heels.'

Arms 'Put your hands out in front of you.'

'Turn your hands over and make a fist.'

'Pinch your index finger and thumb together.'

'Touch the tips of your fingers with your thumb.'

Squeeze metacarpophalangeal joints.

'Put your hands together/put your hands back-to-back.'

'Reach up and touch the sky.'

'Look up at the ceiling.'

'Put your hands behind your neck.'

Legs Feel for effusion at the knee.

'Bend and then straighten your knee.' (Active movement of knees and examiner feels for crepitus.) Passive flexion $\left(90^{\circ}\right)$ with internal rotation of the hip.

Spine
The MSK examination should start with the screening examination known as the paediatric gait arms legs spine (PGALS). This validated screening tool has been designed to facilitate the rapid initial assessment of a child with MSK pain. It is quick and easy to do and easily accepted by patients. The PGALS starts with 3 screening questions and moves to several manoeuvres that are specifically choreographed to reveal abnormalities in the MSK system in children. It is summarised in Table 4 and is published here with permission from the authors. ${ }^{[10]}$

If an abnormality is identified on PGALS, a full MSK examination should be undertaken, including a thorough examination of all joints. Guidelines on specific joint examinations can be viewed online (see Online resources below). This web-based resource is focused on providing information to non-rheumatologists on the examination and management of rheumatic diseases. Specific points of interest in the examination of children with JIA are given in Table 5.

\section{Laboratory investigations}

Laboratory investigations in JIA are used mainly to exclude other diagnoses or to investigate complications of JIA or its treatment. The minimum investigations are given in Table 6 .

\section{Conventional radiography}

Radiographs in children with MSK disease are a standard firstline investigation that is widely available and affordable. In the context of the diagnosis of JIA, radiographs are useful in

Table 5. The examination of a child with juvenile idiopathic arthritis

Pain Extreme pain with motion could indicate a fracture or septic arthritis.

Mild pain with swelling or loss of range of motion is usual for JIA.

Amplified pain syndromes may have severe hyperaesthesia.

Range of A child should have a full range of motion in all joints. motion Significant and longstanding arthritis will frequently cause deviations from the full range of motion.

Swelling Swelling may be hard to assess, especially in the elbows, shoulders and ankles of younger children. When swelling is identified, it is important to consider the nature of the swelling: fluid is fluctuant, synovium boggy and compressible.

Atrophy Atrophy can be subtle and a sign of functional loss in a limb.

Colour Joints are frequently warm in chronic and acute arthritis, but a red joint is highly suggestive of septic arthritis or osteomyelitis.

Localised Longstanding arthritis causes localised growth growth disturbances. The affected limb grows longer and thicker disturbances than the unaffected limb. Leg length discrepancy is a useful marker of chronic arthritis. Evaluating the child from behind for pelvic tilt can assess this.

Eye examination Certain types of JIA are associated with uveitis. your mouth.

Lateral flexion of the spine: 'Try to touch your shoulder with your ear.'

Observe spine from behind.

'Can you bend and touch your toes?': observe curve of spine from side and behind. related arthritis, the uveitis of JIA can be completely asymptomatic. Initially, slit lamp examination is required to identify uveitis. Later in the disease, a distorted pupil (caused by posterior synechiae), glaucoma or cataracts may be present
While a painful red eye is associated with enthesitis- 


\section{Table 6. Special investigations in juvenile idiopathic arthritis}

Full blood count Useful in differentiating the inflammatory from the non-inflammatory disease. Thrombocytopenia and peripheral blood smear may identify haematological malignancies.

ESR Fibrinogen produced by the liver in response to cytokine stimulation causes high ESR seen in inflammation. Nonspecific inflammatory marker, more useful in monitoring of inflammatory diseases than diagnosis

CRP Produced in the liver in response to cytokine stimulation (IL-6, IL-1 and TNF). The advantages of CRP measurement: it is not influenced by as many variables as the ESR.

ANA/ANF Although they are generally ubiquitous and present in many individuals who do not have autoimmune disease, high titres are associated with autoimmune conditions. Some subtypes of JIA are associated with positive tests for ANA.

$\mathrm{RF}$ and anti-CCP This is the most over-requested and overinterpreted test in children suspected of having a rheumatic disease. As a screening test for JIA it is of virtually no value. A small subgroup of children with RF-positive polyarticular disease will have a positive RF; this test is useful in classifying this cohort.

HLA B27 This major histocompatibility complex type 1 antigen is strongly associated with enthesitisrelated arthritis. It also occurs with greater frequency in children with psoriatic arthritis, inflammatory bowel disease, reactive arthritis and acute anterior uveitis. It is a useful test if one of these conditions is suspected on clinical grounds, but not a good screening tool in the general population.

$\mathrm{ESR}=$ erythrocyte sedimentation rate; $\mathrm{CRP}=\mathrm{C}$-reactive protein; $\mathrm{ANA}=$ antinuclear antibodies; $\mathrm{ANF}=$ antinuclear factor; $\mathrm{RF}=$ rheumatoid factor; anti-CCP $=$ cyclic citrullinated

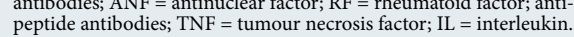

excluding other causes of MSK pain, e.g. fractures or other bony lesions such as osteomyelitis or tumours. They can also give specific information on joint space narrowing, bone erosions, joint alignment, subluxation or ankylosis. It is important to note that the absence of abnormalities on X-ray examination does not exclude acute or chronic arthritis.

Other imaging modalities are summarised in Table 7.

\section{Treatment of JIA}

Early recognition of JIA and referral to specialist and multidisciplinary services for management improves the prognosis. In all cases the goal of treatment is complete disease remission and normal physical and social development. The many new medications currently available for the treatment of JIA make this achievable.

\section{Non-pharmacological therapy}

Physiotherapy and occupational therapy are essential in the management of JIA. These therapies improve joint range of motion
Table 7. Ultrasound and magnetic resonance imaging in juvenile idiopathic arthritis

\begin{tabular}{ll}
\hline Ultrasound & Useful in the diagnosis of children suspected of having \\
inflammatory joint disease. Gives good anatomical \\
detail; can also reliably show joint effusions, synovial \\
hypertrophy, inflammation and inflamed tendon \\
sheaths and entheses. Early erosions and osteophytes \\
can be identified. Quality depends on experience and \\
training of ultrasonographer. \\
MRI gives very accurate information on bone and \\
soft-tissue structure of the joint. Sensitive tool \\
for assessing inflammation and oedema. Utility \\
limited by cost and availability as well as the need \\
for sedation or anaesthetic in young children. \\
Gold standard examination in terms of detail and \\
accuracy.
\end{tabular}

and mobility and thereby prevent permanent deformity. They can help manage pain and encourage children to exercise within the limits of their abilities. This physical activity is safe and important in improving the quality of life of children with JIA. Social workers and mental health experts are often also needed to address the psychosocial impact of pain and chronic illness on the child and family unit.

\section{Pharmacological therapy}

\section{Non-steroidal anti-inflammatory drugs (NSAIDs)}

NSAIDs are used for the management of joint pain and stiffness. All NSAIDs are equally effective and choice depends on cost, tolerability, dosing schedule and formulation. Gastrointestinal side-effects are common and patients requiring long-term NSAIDs should have regular renal and liver function monitoring.

\section{Corticosteroids}

Systemic oral and parenteral corticosteroids are used in the treatment of JIA, usually as bridging therapy while disease-modifying antirheumatic drug (DMARD) regimens take effect. They are particularly useful in severe polyarthritis and systemic JIA. Importantly, they do not induce remission, and care should always be taken to minimise exposure, given the potential side-effects of long-term use. Concurrent calcium and vitamin D supplementation is necessary to prevent osteopenia.

Intra-articular steroid (IAS) injections have been shown to induce sustained remission when used as monotherapy or in conjunction with methotrexate. ${ }^{[1]]}$ Triamcinolone hexocetonide is thought to have superior efficacy to methylprednisolone acetate. IAS injections are usually well tolerated, but in young children should preferably be done under sedation or general anaesthetic. Subcutaneous atrophy at the injection site can occur in approximately $2 \%$ of cases. ${ }^{[12]}$

\section{Disease modifying anti-rheumatic drugs}

DMARDs are used as maintenance therapy to control disease activity. They are safe and effective in children and their use ideally limits the need for long-term NSAIDs and corticosteroids. Early introduction of DMARDs has been shown to decrease disease severity and improve prognosis. Table 8 summarises the important prescribing details of synthetic DMARDs. ${ }^{[13-15]}$ 
Table 8. Synthetic disease-modifying anti-rheumatic drugs

\begin{tabular}{|c|c|c|c|c|}
\hline DMARD & Dosing & Common side-effects & Monitoring & Comments \\
\hline MTX & $\begin{array}{l}15 \mathrm{mg} / \mathrm{m}^{2} \text { weekly po or } \\
\text { subcutaneously }\end{array}$ & $\begin{array}{l}\text { Nausea and vomiting, } \\
\text { mouth ulcers, transient } \\
\text { transaminitis }\end{array}$ & $\begin{array}{l}\text { FBC and LFTs every } \\
3 \text { months }\end{array}$ & $\begin{array}{l}\text { Folic acid supplementation prevents } \\
\text { GIT side-effects and ulcers } \\
\text { Subcutaneous dosing can overcome } \\
\text { poor response to oral therapy or } \\
\text { GIT side-effects }\end{array}$ \\
\hline Sulphasalazine & $20-25 \mathrm{mg} / \mathrm{kg}$ twice daily po & $\begin{array}{l}\text { Rash, GIT upset, } \\
\text { myelosuppression, liver } \\
\text { function abnormalities }\end{array}$ & $\begin{array}{l}\text { FBC and LFTs every } \\
3 \text { months }\end{array}$ & $\begin{array}{l}\text { Possible additive hepatotoxicity } \\
\text { with MTX }\end{array}$ \\
\hline Chloroquine & 5.0 - $6.5 \mathrm{mg} / \mathrm{kg}$ daily po & $\begin{array}{l}\text { GIT upset, rash, headache, } \\
\text { visual changes }\end{array}$ & $\begin{array}{l}\text { FBC, LFTs and U and } \\
\text { E every } 3 \text { months }\end{array}$ & Test visual acuity annually \\
\hline Leflunomide & $\begin{array}{l}\text { Loading dose: } 100 \mathrm{mg} \\
\text { daily } \times 3 \text { doses po } \\
\text { Maintenance dose: } 20 \mathrm{mg} \text { daily po }\end{array}$ & $\begin{array}{l}\text { GIT upset, headache, rash, } \\
\text { alopecia }\end{array}$ & $\begin{array}{l}\text { FBC and LFTs every } \\
3 \text { months }\end{array}$ & $\begin{array}{l}\text { Consider when MTX is not } \\
\text { tolerated }\end{array}$ \\
\hline
\end{tabular}

Table 9. Biologic disease-modifying anti-rheumatic drugs

\begin{tabular}{|c|c|c|c|c|c|}
\hline Class & Drugs & Administration & Common side-effects & Precautions & Monitoring \\
\hline TNF inhibitors & $\begin{array}{l}\text { Etanercept } \\
\text { Adalimumab } \\
\text { Infliximab } \\
\text { Golimumab }\end{array}$ & $\begin{array}{l}\text { Etanercept S/C once } \\
\text { weekly } \\
\text { Adalimumab S/C every } \\
2 \text { weeks } \\
\text { Infliximab IV } 2 \text { - 8-weekly } \\
\text { Golimumab S/C monthly }\end{array}$ & $\begin{array}{l}\text { Hypersensitivity } \\
\text { infusion reactions }\end{array}$ & $\begin{array}{l}\text { For all biologics: } \\
\text { omit biologic } \\
\text { during active } \\
\text { infections } \\
\text { Avoid in TB }\end{array}$ & $\begin{array}{l}\text { For all biologics: TB } \\
\text { screening before starting, } \\
\text { then annually } \\
\text { FBC, LFT, U and E every } \\
3 \text { months }\end{array}$ \\
\hline IL inhibitors & $\begin{array}{l}\text { Anakinra (IL-1) } \\
\text { Tocilizumab (IL-6) } \\
\text { Canakinumab (IL-1 } \beta \text { ) }\end{array}$ & $\begin{array}{l}\text { Anakinra S/C daily } \\
\text { Tocilizumab IV every } \\
2 \text { weeks } \\
\text { Canakinumab S/C } \\
\text { monthy }\end{array}$ & $\begin{array}{l}\text { Injection site or } \\
\text { infusion } \\
\text { reactions }\end{array}$ & Avoid live vaccines & $\begin{array}{l}\text { Use MTX concomitantly } \\
\text { to prevent } \\
\text { immunogenicity }\end{array}$ \\
\hline B-cell inhibitor & Rituximab & IV every week $\times 2$ doses & Infusion reactions & & CD19 count for rituximab \\
\hline $\begin{array}{l}\text { T-cell } \\
\text { co-stimulatory } \\
\text { modulator }\end{array}$ & Abatacept & IV once monthly & $\begin{array}{l}\text { Infusion reactions } \\
\text { uncommon }\end{array}$ & & \\
\hline
\end{tabular}

\section{Biologic agents}

The advent of biologic agents has significantly enhanced the treatment options for children with JIA and made complete disease remission an achievable outcome. The choice of agent depends on JIA subtype, but patient preference with regard to route and frequency of admission should also be considered. These agents are expensive and access to them requires careful motivation to the healthcare system involved. Table 9 summarises the important prescribing details of biologic DMARDs. ${ }^{[16-21]}$

\section{Conclusion}

JIA is not a rare disease and the complications of untreated JIA are significant. All physicians dealing with children should know when to suspect or diagnose this condition and perform the relevant investigations. Early appropriate referral will improve outcomes in patients with this disease. The modern arsenal of investigations and management greatly improves the outcome of patients with JIA. Other causes of joint pain or MSK morbidity in children range from benign to potentially life threatening.

\section{Practice points}

- MSK complaints are very common in children.

- Early and correct diagnosis and referral of patients with JIA are important.

- JIA is predominantly a clinical diagnosis based on pattern recognition.

- RF has no value in screening for patients with JIA.

- Remission can be achieved in the majority of patients using traditional DMARD therapy.

- Targeted cytokine therapy such as tumour necrosis factor inhibitors offers good therapeutic options to those not responding to traditional DMARDs.

\section{References}

1. De Inocencio J. Epidemiology of musculoskeletal pain in primary care. Arch Dis Child 2004;89(5):431.

2. Foster HE, Cabral DA. Is musculoskeletal history and examination so different in paediatrics? Best . Foster HE, Cabral DA. Is musculoskeletal history and examination so different in paediatrics
Pract Res Clin Rheumatol 2006;20(2):241-262. [http://dx.doi.org/10.1016/j.berh.2005.11.001]

3. Goodman J, McGrath P. The epidemiology of pain in children and adolescents: A review. Pain 1991;46(3):247-264. [http://dx.doi.org/10.1016/0304-3959(91)90108-A]

4. Fischer S, Beattie T. The limping child: Epidemiology, assessment and outcome. J Bone Joint Surg Br 1999;81(6):1029-1034. [http://dx.doi.org/10.1302/0301-620X.81B6.9607] 
5. Albers HM, Wessels JA, van der Straaten RJ, et al. Time to treatment as an important factor for the response to methotrexate in juvenile idiopathic arthritis. Arthritis Rheum 2009;61(1):46-51. [http:// dx.doi.org/10.1002/art.24087]

6. Manners PJ, Bower C. Worldwide prevalence of juvenile arthritis: Why does it vary so much? I Rheumatol 2002;29(7):1520-1530.

7. Petty RE, Southwood TR, Manners P, et al. International League of Associations for Rheumatology classification of juvenile idiopathic arthritis: Second revision, Edmonton, 2001. J Rheumatol 2004;31(2):390-392

8. Weakley K, Esser M, Scott C. Juvenile idiopathic arthritis in two tertiary centres in the Western Cape, South Africa: University of Cape Town; 2011. Pediatr Rheumatol Online J 2012;10(1):35. [http:// dx.doi.org/10.1186/1546-0096-10-35]

9. Prakken B, Albani S, Martini A. Juvenile idiopathic arthritis. Lancet 2011;377(9783):2138-2149. [http://dx.doi.org/10.1016/S0140-6736(11)60244-4]

10. Foster HE, Kay LJ, Friswell M, Coady D, Myers A. Musculoskeletal screening examination (pGALS) for school-age children based on the adult GALS screen. Arthritis Rheum 2006;55(5):709-716. [http:// dx.doi.org/10.1002/art.22230]

11. Zulian F, Martini G, Gobber D, Agosto C, Gigante C, Zacchello F. Comparison of intra-articula triamcinolone hexacetonide and triamcinolone acetonide in oligoarticular juvenile idiopathic arthritis. Rheumatology (Oxford) 2003;42(10):1254-1259. [http://dx.doi.org/10.1093/rheumatology/keg358]

12. Scott C, Meiorin S, Filocamo G, et al. A reappraisal of intra-articular corticosteroid therapy in juvenile idiopathic arthritis. Clin Exp Rheumatol 2010;28(5):774-781.

13. Beresford $M$, Baildam E. New advances in the management of juvenile idiopathic arthritis - 1: Nonbiological therapy. Arch Dis Child Educ Pract Ed 2009;94(5):144-150. [http://dx.doi.org/10.1136/ adc.2008.144576]

14. Gowdie PJ, Shirley M. Juvenile idiopathic arthritis. Pediatr Clin North Am 2012;59(2):301-327. [http:// dx.doi.org/10.1016/j.pcl.2012.03.014
15. Takken T, van der Net JJ, Helders PP. Methotrexate for treating juvenile idiopathic arthritis. Cochrane Database Syst Rev 2001;(4):CD003129. [http://dx.doi.org/10.1002/14651858.cd003129]

16. Beresford $M$, Baildam $E$. New advances in the management of juvenile idiopathic arthritis -2 : The era of biologicals. Arch Dis Child Educ Pract Ed 2009;94(5):151-156. [http://dx.doi.org/10.1136/ era of biologicals.
adc. 2009.170860]

17. Giannini E, Ilowite N, Lovell D, et al. Long-term safety and effectiveness of etanercept in children with selected categories of juvenile idiopathic arthritis. Arthritis Rheum 2009;60(9):2794-2804. [http:// dx.doi.org/10.1002/art.24777

18. Katsicas MM, Russo RA. Use of adalimumab in patients with juvenile idiopathic arthritis refractory to etanercept and/or infliximab. Clin Rheumatol 2009;28(8):985-988. [http://dx.doi.org/10.1007/s10067 009-1162-7]

19. Quartier P, Allantaz F, Cimaz R, et al. A multicentre, randomised, double-blind, placebo-controlled trial with the interleukin-1 receptor antagonist anakinra in patients with systemic-onset juvenile idiopathic arthritis (ANAJIS trial). Ann Rheum Dis 2011:70(5):747-754. [http://dx doi.org/10.1136/ ard.2010.134254]

20. De Benedetti $\mathrm{F}$ Brunner $\mathrm{H}$, Ruperto $\mathrm{N}$, et al Efficacy and safety of tocilizumab (TCZ) in patients with systemic juvenile idiopathic arthritis (SJIA): Tender 52-week data. Pediatr Rheumatol 2011;9(Suppl 1):164. [http://dx.doi.org/10.1186/1546-0096-9-S1-P164]

21. Lovell DJ. Long-term efficacy and safety of adalimumab for up to 6 years in patients with juvenile idiopathic arthritis. ACR/ARHP scientific meeting, November 2011, Chicago, USA.

\section{Online resources}

Paediatric musculoskeletal matters. User-friendly and elegant resource on paediatric musculoskeletal conditions for students or medical personnel working with children. Developed by Prof. Helen Foster from Newcastle University, UK: www.pmmonline.org 